Rev Chil Salud Pública 2012; Vol $16(3): 264-271$

Investigación en historia de la salud pública

\title{
Historia / historia de la enfermedad / historia de la salud pública*
}

\author{
HISTORY / HISTORY OF DISEASE / HISTORY OF PUBLIC HEALTH
}

El gran historiador holandés Johan Huizinga solía decir algo así como "escribimos la historia del mejor modo que podemos". Es una afirmación falsamente modesta que de todos modos suscribo con energía. No se trata de una proposición complaciente a cualquier cosa, a un vale todo. Tengo mis predilecciones, gustos, prioridades, reservas. Me interesa la historia bien narrada que busca analizar el pasado contextualizando eventos y circunstancias, hilvanándolos entre sí de modo de poder reconstruir y explicar procesos. Me impongo lidiar con el pasado como una totalidad donde cuentan discursos, políticas y experiencias. De una parte, se trata de mirar lo que ya pasó como una suerte de mundo complejo, contradictorio y multifacético. De otra, reconstruir ese pasado con evidencias dispares, discontinuas, sesgadas e incompletas que luego se entretejen con más o menos sofisticación. Allí están de las evidencias estadísticas -que organizan la realidad de una cierta forma -a los discursos de los políticos, que muchas veces son sólo discursos y no políticas efectivamente aplicadas esto es, intervenciones que de algún modo modifican la realidad. Del registro periodístico -que no es necesariamente un cuidadoso espejo de los aconteceres cotidianos- a las reconstrucciones más o menos ficcionales que ofrecen los relatos literarios. De los recuerdos individuales o grupales -esto es, memoria histórica, que no es sinónimo de historia- a las imágenes desplegadas en una foto, una escena de una película o una propaganda. Del mundo de las ideas formuladas con más o menos claridad -las que apuntan a cambiar las cosas en algún sentido y las que apuntan a mantenerlas tal como están- al de las ideologías que vanamente se pretenden consistentes, omnicomprensivas, sin fisuras. De las acciones u omisiones de ciertas instituciones y del Estado -a veces muy poco significativas en la vida cotidiana, otras no- a las de las organizaciones sociales, con frecuencia dispuestas a invocarse la obligación y el derecho de hablar en nombre de la gente o de un cierto grupo. La lista puede seguir porque todas esas evidencias son útiles, especialmente si se hace un uso crítico de ellas. Disponer de una, cien o mil de esas evidencias puede ser irrelevante si quien las lee no aspira a contextualizarlas. Claro que es mejor tener muchas, pero es bueno tener presente que la acumulación de datos sin interpretación está más cerca del anticuario que de la historia. Sin duda, los datos y eventos adquieren relevancia cuando son parte de procesos.

En ese empeño por contextualizar, trabajamos con marcos teóricos y tratamos de ser más o menos consistentes metodológicamente. Así, y con mayor o menor cautela, abrevamos en diversas tradiciones, evitando encorsetar la compleja trama del pasado usando -y abusando- de las teorías y metodologías, tanto las de turno, como las que tuvieron su momento de gloria y ya perdieron

DIEGO ARMUS ${ }^{(1)}$

(1) Swarthmore College 500 College Avenue Swarthmore, PA 19081-1397. Estados Unidos. darmus1@swarthmore.edu relevancia o presencia. Las teorías -sus categorías, sus modelos- así como las

\footnotetext{
* Estas notas retoman, sin modificaciones sustanciales, una presentación realizada en abril de 2012 en la Escuela de Salud Pública de la Universidad de Chile.
} 
metodologías sirven en la medida en que permiten empezar a ordenar y leer ese bagaje de evidencias discontinuas, incompletas y parciales. Pero sirven poco, o mal, cuando la reconstrucción del pasado que se termina haciendo resulta de un más o menos indisimulado empeño por forzar la realidad pretérita a la teoría. Algo similar sucede con las generalizaciones. Como con los modelos teóricos, son tan necesarias como riesgosas puesto que pueden terminar borrando o aplanando -aún sin buscarlo- la rica urdimbre que resulta de eventos singulares y procesos inevitablemente anclados en un momento histórico y lugar definidos. Así, la historia se prefigura como una película -no tanto como una fotografía- donde el cambio y la continuidad, lo nuevo y lo viejo, lo que perdura y lo que se desvanece, conviven tensionados. Algunas de las dimensiones de esa historia también están presentes de algún modo en otros lugares y otros tiempos, y por eso son pasibles de generalizarse. Pero marcadas implacablemente por el tiempo y el lugar, esa trama es ante todo específica y peculiar. Está saturada de incertidumbres y ambigüedades, cruzada por el azar y las circunstancias, condicionada por estructuras sobre las que la acción humana puede incidir pero solo hasta un cierto punto.

Escribir historia con estas premisas no es cosa sencilla. $Y$ no lo es porque en el fondo, lo que está marcando a esa reconstrucción del pasado es una ambiciosa aspiración signada por la contextualización, el diálogo interdisciplinario y un deliberado empeño dirigido a aprehender la totalidad de la experiencia humana.

La historiografía sobre la enfermedad y la salud descubre un panorama disparejo donde con frecuencia las aspiraciones de contextualización no son más que eso, aspiraciones. En varios artículos y libros intenté dar cuenta de los distintos modos en que se estaba escribiendo sobre la salud y la enfermedad en perspectiva histórica. Indicaba que en la historiografía contemporánea, incluyendo la de América Latina, las últimas tres décadas no solo reconocen un sostenido esfuerzo por renovar la tradicional historia de la medicina sino también transformaron a la salud y a la enfermedad en promisorios objetos de reflexión por parte de las ciencias sociales y las humanidades. ${ }^{*}$

En este contexto de sostenida afirmación del campo de la historia de la enfermedad y la salud se fueron perfilando tres modos o estilos de abordar y narrar el pasado que despliegan énfasis diversos y también muchas superposiciones: la nueva historia de la medicina, la historia de la salud pública y la historia sociocultural de la enfermedad.

La nueva historia de la medicina busca tensionar la historia natural de una patología y los inciertos desarrollos del conocimiento biomédico, discutir no solo el contexto -en particular el científico, pero también aunque en menor medida el social, cultural y político- en el cual algunos médicos, investigadores, instituciones y tratamientos "triunfaron", haciéndose un lugar en la historia, sino también el de aquellos otros que quedaron perdidos en el olvido.

La historia de la salud pública tiende a enfocarse en el poder, la política, el Estado, las instituciones y la profesión médica. En gran medida es una historia donde la medicina pública suele aparecer en clave progresista -intentando ofrecer soluciones eficaces para la lucha contra las enfermedades del mundo moderno- y donde las relaciones entre las instituciones de salud y las estructuras económicas, sociales y políticas están en el centro de la narrativa. Discute no tanto los problemas de la salud individual sino la de los grupos, estudia las acciones políticas para preservar o restaurar la salud colectiva y suele enfocar su atención en los momentos en que el Estado o algunos sectores de la sociedad han impulsado iniciativas concretas resultantes de una evaluación donde los factores médicos y epidemiológicos cuentan tanto como los políticos, económicos, culturales, científicos y tecnológicos. Es una historia que se pretende útil e instrumental. Quienes la practican conforman un grupo variado. Algunos dirían que hacen his-

\footnotetext{
* Diego Armus, "Disease in the Historiography of Modern Latin America", en Disease in the History of Modern Latin America: From Malaria to AIDS, (ed.) Diego Armus (Durham y Londres: Duke University Press, 2003); Diego Armus, "Legados y tendencias en la historiografía sobre la enfermedad en América latina moderna" en Avatares de la medicalización en América latina, 1870-1970 (ed.) Diego Armus (Buenos Aires: Lugar Editorial, 2005); Diego Armus y Adrián López Denis, "Disease, Medicine, and Health, 1500-1950", en The Oxford Handbook of Latin American History, (ed.) José Moya (New York: Oxford University Press, 2011).
} 
toria "de" la salud pública puesto que tienden a investigar el pasado con el objetivo de encontrar allí pistas que, se supone, deberían reducir -de modo no específico sino general- las inevitables incertidumbres que marcan a todo proceso de toma de decisiones en materia de salud pública en el presente. Otros, en cambio, no ocultan que hacen historia "en" la salud pública -no tanto "de" la salud pública- toda vez que ellos mismos se reconocen como activos protagonistas en la formulación e instrumentalización de proyectos, visiones y políticas contemporáneas para las que la historia sería una suerte de insumo. De fuerte tono estructuralista -una perspectiva que parece haber perdido el fervor que gozaba hace dos o tres décadas- o crecientemente marcada por un énfasis neo-institucionalista y, en consecuencia, atento a los muy diversos caminos pasibles de ser recorridos por las políticas públicas- la historia de la salud ofrece una discreta variedad de enfoques.

La historia sociocultural de la enfermedad resulta del trabajo de historiadores, demógrafos, sociólogos, antropólogos y críticos culturales que, desde sus propias disciplinas y participando del influyente giro historicista de las últimas décadas, han descubierto la riqueza, complejidad y posibilidades de la enfermedad y la salud, no solo como problema sino también como excusa o recurso para discutir otros tópicos. Apenas dialoga con la biomedicina y se concentra en los procesos de profesionalización, los avatares de la medicalización, las instituciones y prácticas de asistencia, disciplinamiento y control médico-social, el rol del Estado en la construcción de la infraestructura sanitaria, las condiciones materiales de vida y de trabajo así como las asociadas con la raza y el género y sus efectos en la vida cotidiana y en la mortalidad y la morbilidad, la historización de lo normal y lo patológico, las ideas sobre el cuerpo individual y social, las metáforas asociadas a una cierta enfermedad.

Se trata de narrativas que reconocen en las enfermedades no solo la existencia de algún tipo de sustrato biomédico -aquello de que una enfermedad es algo más que un virus o una bacteria- sino también, y tal como lo ha escri- to uno de los más influyentes historiadores en este campo, una oportunidad para desarrollar y legitimar políticas públicas, facilitar y justificar la creación y el uso de ciertas tecnologías y desarrollos institucionales, canalizar ansiedades sociales de todo tipo, descubrir aspectos de las identidades individuales y colectivas, sancionar valores culturales y estructurar la interacción entre enfermos y proveedores de atención a la salud. Así, este modo de escribir la historia de las enfermedades asume que una dolencia, mal 0 patología existe luego de que se ha llegado a un acuerdo que revela que se la ha percibido como tal, denominado de un cierto modo y respondido con acciones más o menos específicas. *

De modo que la historiografía de la enfermedad y la salud en América Latina refleja bastante adecuadamente esa variedad de enfoques, que tienden a entender a la medicina como un terreno incierto, donde lo biomédico está penetrado por la subjetividad humana y donde la biología está connotada por fenómenos sociales, culturales, políticos y económicos. La calidad de este corpus es inevitablemente despareja y sus perspectivas diversas, marcadas por el pluralismo temático, metodológico y de estilos narrativos. A su modo expresan la fragmentación de los tiempos historiográficos que corren, cuando las grandes narrativas históricas están ausentes. Sea porque campea un cierto escepticismo frente a las grandes narrativas, sea porque la dinámica del trabajo académico -con frecuencia hasta el hartazgo o el absurdo- demanda el recorte temático, esta fragmentación parece estar ayudando a explicar más y mejor las relaciones entre enfermedad, salud e historia. Pero esa misma fragmentación, con frecuencia, lleva a ignorar a la contextualización, una dimensión clave junto al cambio y la continuidad, a lo que perdura y lo que se modifica, a la especificidad que da el cruce del tiempo y el espacio en cualquier esfuerzo de reconstrucción del pasado. Así, pareciera ser necesario asumir la fragmentación historiográfica y, al mismo tiempo, aspirar a contextualizar, tanto como se pueda, la narrativa histórica.

Yo celebro este prolífico pluralismo temático, metodológico y de estilos narrativos. Y lo cele-

\footnotetext{
* Charles Rosenberg, "Framing Disease: Illness, Society and History", en Framing Disease: Studies in Cultural History, (eds.) Charles Rosenberg y Jeanne Golden (New Brunswick: Rutgers University Press, 1992), xiii.
} 
bro, no tanto por todo lo que se ha producido -hay mucho que no me gusta o con lo que no coincido o que está muy alejado a mi estilo de contar la historia o articular un argumento- sino precisamente por su diversidad. Muchos de esos trabajos son muy puntuales, incluso bastante poco imaginativos. Pero no dudo en subrayar que son imprescindibles en esta instancia en que sabemos muy poco de temas y cuestiones muy básicas. Sin esos estudios es imposible hacer refinadas y elaboradas síntesis y explicaciones de procesos muy complejos. Más aún, sin esa base empírica se hace muy difícil o riesgoso usar una cierta teoría o metodología, explicitada o no.

No tengo dudas de que bajo la muy amplia etiqueta de la historia de la salud y la enfermedad no solo hay un promisorio campo de estudios en vías de definición y reformulación sino también muchas preocupaciones con alguna trayectoria -la historia demográfica, de las profesiones e instituciones, de las políticas públicas, de la biomedicina- que comenzaron a ampliar su agenda, se hicieron más ambiciosas, desbordaron sus límites originarios y creo que ganaron en contextualización.

Sabemos que son tiempos en que las grandes narrativas históricas están ausentes. No sé si volverán alguna vez. Lo que es seguro es que el tono de estos tiempos historiográficos es el de la fragmentación. Tal vez porque somos más escépticos de las grandes narrativas, porque la dinámica de la vida académica demanda el recorte temático, con frecuencia hasta el hartazgo o el absurdo, porque -nos guste o no- así parece que se sobrevive en el mundo académico. Y si a veces esa fragmentación parece estar ayudando a saber y en ocasiones incluso explicar más y mejor las relaciones entre enfermedad, salud e historia, a veces también juega en contra y hace perder una dimensión clave en nuestro trabajo. Me refiero a la contextualización. Junto al cambio y la continuidad, lo que perdura y lo que se modifica, junto a la especificidad que da el cruce del tiempo y el espacio, la contextualización le da sentido a la narración histórica.

Diría que ese es, al menos para mí, el gran desafío. Se trata de asumir la fragmentación dominante de la que resultan nuestros objetos de estudio pero aspirar a contextualizarlos. Creo que no hay recetas para lograrlo. Con todo, me animo a listar una serie de asuntos que, creo, son pertinentes a ese esfuerzo de contextualización. Debo aclarar, con todo, que se trata de preocupaciones de un historiador socio-cultural, alguien que usa la teoría pero sin venerarla con espíritu cuasi religioso, alguien que busca ser metodológicamente consistente pero evitando la rigidez, alguien que cree y trata de cultivar la narrativa histórica -aquello de contar una historia-, alguien que se propone hacer todo esto con una respetable base empírica y no con dos citas de diario, un capítulo de una novela y abundantes referencias teóricas o indicaciones originadas en la historiografía norteamericana, inglesa o francesa.

Paso entonces a hacer algunas observaciones sobre ciertos tópicos que al día de hoy me interesan cuando escribo sobre la historia de una enfermedad.

\section{El registro de la enfermedad como experiencia individual}

Lo sabemos bien: las historias clínicas tienen muchas posibilidades y también muchas limitaciones. Me detengo en las limitaciones. Primero el problema del número: ¿cuántas necesitamos? ¿Una, cien, mil historias clínicas? Mejor más que menos, pero sin duda la cuestión no es solamente cuantitativa porque el problema con que estamos lidiando es la dimensión individual de la enfermedad.

Es curioso, nuestro sistemático esfuerzo por trabajar con la enfermedad como un hecho biosocial que circula en la esfera pública nos ha llevado a dirigir nuestra mirada a la enfermedad como proceso colectivo y nos olvidamos que no todos los cuerpos se enferman por igual (y no me estoy refiriendo a aquello de que los pobres se enferman más que los ricos sino que algunos pobres se enferman más que otros pobres).

Por otra parte, la historia clínica es un registro que resulta de la mirada y práctica del prestador de salud, en general un médico, pero no siempre. Quiero decir: trabajar con historias clínicas no significa haber atrapado la perspectiva del enfermo. Es una conclusión ingrata, pero necesaria. Ser conscientes de esta limitación no implica dejar de lado la difícil tarea de tratar de jerarquizar el lugar y la perspectiva del enfermo en la narrativa histórica. 
Algo parecido ocurre con la memoria individual de una patología. La memoria nos acerca a la subjetividad y al recuerdo individualizado de la experiencia de la enfermedad. No es necesario indicar que darle lugar a esta dimensión es, de por sí, un notable hallazgo y una justa reincorporación del enfermo en la historia. Pero es preciso tener presente que la memoria -tanto la individual como la colectiva- no es toda la historia.

\section{La dimensión global, regional y local de una enfermedad}

Durante un tiempo la historia de una enfermedad en, digamos, Inglaterra, era escrita como si fuera una historia global de esa enfermedad. Más tarde se fue entendiendo que era preciso dar cuenta de peculiaridades locales o regionales, toda vez que la historia de la enfermedad como fenómeno colectivo, sus cambios y continuidades, transcurren en un lugar y tiempo específicos. Más aun, lo que ahora aparece tranquilamente etiquetado como enfermedad tropical -estoy pensando en la malaria, pero probablemente no sea el único caso- también tuvo su historia en zonas no tropicales.

Este nuevo y jerarquizado lugar de lo local, sin embargo, no debe hacer perder de vista que, en efecto, las enfermedades son procesos trashumantes que si bien no florecen del mismo modo en todos lados, sí comparten algunas características. Este registro global solo puede hacerse cuando se dispone de suficientes estudios locales. Pero, otra vez, cabe preguntarse: ¿cuántos estudios locales son suficientes para escribir una historia global de una enfermedad? No tengo una respuesta. Lo que sí sé es que no me satisfacen las historias globales de una enfermedad armadas solamente, digamos, sobre casos del mundo anglo-americano a los que se agregan sus periferias coloniales 0 pos-coloniales. Estoy seguro que ustedes conocen esos trabajos que vienen de la academia inglesa o norteamericana y espero que ustedes compartan mi disgusto. Para decirlo de otro modo: por incluir la India en ese escenario no se puede pensar que el caso brasilero está cubierto, o mencionar los casos de Australia y Nueva Zelanda no debe hacer suponer que se puede prescindir de leer lo que hay escrito sobre Argentina o Chile.
En fin, se me ocurre que una buena historia global de una enfermedad debería tomar la forma de un ensayo o debería ser como las buenas historias de las diásporas y los grupos migratorios, donde se busca tensionar similitudes y diferencias resultantes de procesos macroestructurales -que en el caso de la enfermedad deben sumar la dimensión biológica o natural- y todo lo que resulta de procesos definitivamente locales.

\section{La periodización en la historia de las enfermedades}

Si los sociólogos y los cientistas políticos se preocupan poco, o nada, por la periodización, nosotros historiadores somos -o deberíamos ser- más respetuosos del paso del tiempo, más cuidadosos en organizar de algún modo los cambios y las continuidades. Me parece que la periodización de la historia de las enfermedades debe reconocer por lo menos dos cuestiones. En primer lugar, los tiempos largos de lo que podríamos llamar la historia natural de la enfermedad -siguiendo a Rosenberg-, los tiempos donde cuentan el descubrimiento y encuadre de la patología, la construcción de los necesarios consensos, la búsqueda y logro o fracaso de respuestas que lleven al control, erradicación y la desaparición de la enfermedad.

En segundo lugar, los tiempos relativamente más cortos marcados o atados a los avatares generales de una historia necesariamente más específica y acotada a una ciudad o a un país. En este territorio, el problema es dejarse tentar por la periodización ofrecida por la historia política. Lo digo de otro modo y mucho más directamente: ¿Para cuántas enfermedades en la historia de Chile un cambio de gobierno no trajo ningún cambio significativo?

Tal vez para quienes escriben la historia de una enfermedad a partir de los presupuestos de la historia de la salud pública tal como fueron presentados más arriba, estos quiebres en la historia política puedan significar algo. Sin embargo, me parece que las más de las veces esas implicaciones se asumen como tales y no son resultado de un estudio detenido. Lo que me gustaría sugerir con este comentario es que la historia de las políticas públicas enfocadas en una enfermedad es algo más que una propuesta de ley en el Congreso Nacional. En otras pa- 
labras, hay una gran distancia entre discursos públicos sobre una enfermedad y la producción de instrumentos legales, la aprobación de fondos para permitir el desarrollo de una serie de intervenciones, la creación de agencias específicas. Y también una gran distancia entre estas iniciativas discursivas y los resultados efectivos de estas políticas. $Y$ todo esto asumiendo que se disponen de recursos y estrategias que permiten un eficaz control de la enfermedad en cuestión. Todo esto puede leerse como una obviedad. Pero si repasamos mucho -no todo, por suerte- de lo que se ha escrito sobre historia de la salud pública estas precauciones destinadas a diferenciar entre discursos, políticas y resultados no parecen muy desatinadas.

Para cerrar estas observaciones sobre la cuestión de la periodización en la historia de las enfermedades: Los tiempos de una enfermedad se me ocurren más cercanos a los tiempos de la historia de las ideas, largos en su gestación, arrastrando inercias, siempre permeados por circunstancias socio-culturales y políticas locales y, también, por otras sin duda menos locales y más vinculadas con la mayor o menor incertidumbre biomédica que circunda a una cierta enfermedad, esto es, cuánto se sabe y cuánto se puede hacer para controlarla.

\section{La necesidad de reconocer} las ambigüedades que marcan a la medicalización en tiempos de incertidumbres biomédicas frente a una cierta enfermedad

Los ritmos de la medicalización son peculiares y ciertamente imprevisibles Así, hay procesos de profesionalización y especialización médicas que pueden o no consolidarse. También la formulación y puesta en práctica de políticas públicas y dispositivos disciplinadores, asistencialistas y de atención pueden terminar incidiendo positiva o negativamente en la trama social pero no en el sustrato biomédico de una cierta enfermedad y, por ende, de su historia. Y mientras que para algunas enfermedades la biomedicina logró articular respuestas convincentes, efectivas y eficaces, para otras el cuadro puede seguir estando marcado por las incertidumbres biomédicas. El desafío, me parece, es abordar la medicalización como un proceso y no a partir del consolidado perfil que marca a muchas sociedades y vastos sectores sociales -no todoshacia fines del siglo XX y comienzos del XXI.

Discutir la medicalización como proceso significa trabajar con cambios y continuidades en un tiempo y espacio muy definidos. Esto debiera ser una obviedad, especialmente entre historiadores. Pero tan pronto se mira algo de la producción historiográfica, las tentaciones de trasladar modelos teóricos o referencias contemporáneas a los momentos de formación y consolidación del proceso de medicalización, suelen aparecer estudios que concluyen en observaciones, diría yo, casi ridículas. Por ejemplo, los estudios sobre ciudades de medio millón de habitantes supuestamente disciplinadas con tres visitadoras sociales que trabajan en la recién creada asistencia pública municipal... Es que la búsqueda, casi desesperada, del escenario del panóptico puede llegar a desorientar cualquier investigación, asumir que la existencia de discursos disciplinadores supone la presencia -me refiero a una presencia significativa- de prácticas disciplinantes y disciplinadas. Todo esto es aun más relevante en las historias de enfermedades para las cuales sigue dominando la incertidumbre biomédica.

Creo que estos abusos -encontrar consolidados escenarios cuando en verdad se trata de procesos que recién están emergiendo o tomando forma y que no tienen por qué tener un final preestablecido- resultan de una sesgada y muy poco creativa lectura de Michel Foucault, que sigue siendo, quisiera subrayar esto, tremendamente inspirador y sugerente. Queda en nosotros darle historicidad a muchas de sus provocativas proposiciones.

Debo confesar mi tremendo gusto cuando veo que los modelos teóricos se revelan incompetentes al momento de ser testeados en la compleja trama del pasado. No es muy difícil recordar los mandatos -algunos muy efímeros, otros más resistentes al paso del tiempo- que indicaban cuáles eran las preguntas correctas, las categorías que no podían faltar, las citas -muchas veces innecesarias pero obligadas- que se suponía daban el encuadre teórico esperado. En otras disciplinas, estoy seguro, pasaba algo parecido. Creo que tiempo atrás esos mandatos me tranquilizaban porque me daban certezas. 
Ahora, y tal vez porque ya no soy tan joven, estoy cómodo con el pluralismo teórico, metodológico y temático. Michel Foucault, Norbert Elias, Mary Douglas, Carlos Marx, Max Weber, Karl Polanyi... la lista puede seguir. Todos se han revelado más o menos útiles al momento de tratar de interpretar lo que ofrecen las fuentes -me refiero a las orales y escritas, oficiales y no, legas o populares- y reconstruir procesos históricos.

\section{La historia de una enfermedad en el} marco más amplio de la historia de los sistemas de atención de la salud

En cualquier de sus variantes metodológicas, del más relativamente novedoso neo-institucionalismo histórico a los ahora muy cuestionados enfoques estructuralistas, el estudio de los sistemas de atención es un tema importantísimo pero en modo alguno suficiente para discutir la enfermedad y la salud en perspectiva histórica.

Digo insuficiente porque cabe preguntarse ¿Qué pasa cuando las instituciones de ese sistema son apenas relevantes en la vida de la gente, sea porque la gente no las usa porque no cree en lo que estas instituciones puedan ofrecerle, porque no son suficientes o porque la accesibilidad a esos servicios está seriamente limitada por circunstancias individuales y/o colectivas de muy diverso origen, socio-económico, cultural, político? ¿Qué hacer con todo lo que ocurre por fuera de las instituciones de atención, ese plural mundo saturado de prácticas de cuidado y cura distintas a las ofrecidas por la medicina institucionalizada? ¿Cómo estudiar la salud y la enfermedad en tiempos en que la medicalización es incipiente, más un discurso que una práctica realmente instalada en la sociedad? ¿Cómo dar sentido a las subjetividades, reacciones y percepciones de la gente común al momento de lidiar con sus dolencias? ¿Cómo explorar la frecuente distancia entre los así llamados actores -el Estado, los partidos políticos, los colectivos de todo tipo- que se proponen hablar en nombre de ciertos sectores sociales y las prácticas cotidianas de cuidado de salud de esos mismos sectores? ¿Qué hacer con la historia natural de ciertas enfermedades, la que descubre largas impotencias biomédicas donde las instituciones juegan un papel marginal o directamente inexistente?

Son preguntas que nos llevan a la problemática del pluralismo médico, especialmente cuando no se quiere ignorar la perspectiva del enfermo. Hablo de enfermos, no necesariamente pacientes, toda vez que los enfermos devienen en pacientes cuando entran a participar -como actor subordinado- en la trama más o menos cerrada o consolidada de las instituciones de la medicalización.

Pero sabemos muy bien que la gente -yo me incluyo en ese colectivo socialmente diverso y heterogéneo- circula por varios, complementarios o no, sistemas de atención de su salud. Diría que el desafío es discutir esos sistemas con tanta dedicación y sofisticación como lo estamos haciendo con los sistemas de atención de la medicina hegemónica. No es fácil hacerlo y no estoy seguro que podamos hacerlo convincentemente: el asunto no es sencillo para los antropólogos y etnógrafos que lo estudian en el presente, aun más complicado para quienes buscan hacerlo en el pasado, en gran medida por la falta de fuentes e informantes.

En cualquier caso, tener presente esta cuestión puede permitir poner en perspectiva la discusión de la relevancia temporal de los sistemas de atención de la medicina hegemónica. Y si el pluralismo médico destaca el problema del protagonismo de los enfermos, creo que es muy importante tener presente que en la historia de muchas enfermedades, los que la padecen y también devienen en pacientes suelen ser una minoría entre el total de los afectados.

\section{La enfermedad y sus metáforas}

Desde el celebrado ensayo de Susan Sontag no han faltado los empeños en buscar la metáfora de la enfermedad bajo estudio. La intención, creo yo, debe ser celebrada. Sin embargo, es un esfuerzo que debe hacerse con cuidado. Mi impresión es que ciertas enfermedades, en ciertos contextos, efectivamente quedan asociadas a una o varias metáforas. Asimismo, algunas metáforas parecen circular a la manera de registros transnacionales. $Y$ otras parecen ser parte de la experiencia humana. Con todo, y 
se quiere evitar los esencialismos y las generalizaciones abusivas, las metáforas revelan toda su densidad cuando son leídas e interpretadas en un tiempo y espacio definidos, cuando se las aborda como manifestaciones locales.

Dicho esto, también es necesario tomar nota de que algunas enfermedades no producen metáforas.

\section{La contextualización y la aspiración a una historia total de la enfermedad}

La totalidad histórica es escurridiza y probablemente imposible de aprehender. Por eso es tranquilizador hablar de aspiraciones de totalidad. ¿Cómo hacerlo con la historia de las enfermedades? Supongo que hay muchas maneras. Yo trato de integrar en una misma narrativa tres niveles de análisis: el de los discursos, representaciones y metáforas, el de las políticas, el de las experiencias de los enfermos y de los que ofrecen curas. $Y$ si esos tres niveles, por los motivos que fueren -de la falta de fuentes a nuestras propias limitaciones, falta de imaginación o ignorancia- no pueden incluirse en nuestra narrativa, es bueno indicar claramente que estamos escribiendo historia de discursos, o historia de políticas, o historia de experiencias.

Sabemos que son tiempos en que las grandes narrativas históricas están ausentes. No sé si volverán alguna vez. Lo que es seguro es que el tono de estos tiempos historiográficos es el de la fragmentación. Tal vez porque somos más escépticos de las grandes narrativas. Tal vez porque la dinámica de la academia demanda el recorte temático, con frecuencia hasta el hartazgo o el absurdo. Tal vez porque -nos guste 0 no- así parece que se sobrevive en la academia. Y si a veces esa fragmentación parece estar ayudando a saber más y en ocasiones incluso explicar más y mejor las relaciones entre enfermedad, salud e historia, a veces también juega en contra y hace perder una dimensión clave en nuestro trabajo. Me refiero al gran desafío de la contextualización. Junto al cambio y la continuidad, lo que perdura y lo que se modifica, junto a la especificidad que da el cruce del tiempo y el espacio, la contextualización la da sentido a la narración histórica.

Al menos para mí, ese es el gran desafío. Para insistir en algo ya dicho: Asumir la fragmentación dominante de la que resultan nuestros objetos de estudio pero aspirar a contextualizarlos. No hay recetas que nos permitan saber cuánto y cómo contextualizar. Al final de cuentas, nuestro objeto de estudio -la enfermedad y la salud- es multifacético y muy cercano a lo multifacético de la vida misma. Por eso me cuesta creer que una teoría o una metodología nos ayudarán a aprehender esa complejidad. Por eso, creo que tal como lo hacemos en la vida es imprescindible tratar de hilvanar del mejor modo que podamos discursos, representaciones, instituciones, políticas y experiencias. 